\title{
A System Employing Peer Review and Enhanced Computer Assisted Assessment of Querying Skills
}

\author{
Michael de RAADT, Stijn DEKEYSER, Tien Yu LEE \\ Dept. Mathematics and Computing, University of Southern Queensland \\ Toowoomba, Qld, 4350, Australia \\ e-mail: \{deraadt,dekeyser, leet\}@usq.edu.au
}

Received: August 2006

\begin{abstract}
In recent years a small number of web-based tools have been proposed to help students learn to write SQL query statements and also to assess students' SQL writing skills. SQLify is a new SQL teaching and assessment tool that extends the current state-of-the-art by incorporating peer review and enhanced automatic assessment based on database theory to produce more comprehensive feedback to students. SQLify (pronounced as squalify) is intended to yield a richer learning experience for students and reduce marking load for instructors. In this paper SQLify is compared with existing tools and important new features are demonstrated.
\end{abstract}

Key words: peer review, computer assisted assessment, web-based learning, databases, SQL.

\section{Introduction}

SQL is the dominant language for defining and manipulating databases. SQL querying skills are highly valued in the computing industry and as such teaching of SQL in tertiary institutions rivals the importance of programming instruction.

Teaching students to write SQL queries has always been an onerous task for both instructors and students. Students suffer a number of identified difficulties in learning SQL (shown in Section 1.1). To assist students in overcoming these difficulties several tools have been suggested which provide a simple environment for students to write and test queries against databases, receive immediate feedback which is more informative than what can be offered by a Database Management System (Section 1.2).

For instructors, marking queries on paper can be tedious and error prone. Integrating tutoring systems into assessment systems can allow instructors to mark the products of student learning in a more efficient and accurate manner.

Current systems for tutoring and assessment have proven their worth. A new system, SQLify, described here, combines most features present in existing systems:

- visualization of database schema;

- visualization of query processing;

- feedback on query semantics;

- query assessment (using heuristics);

- consistent grading between students and markers; 
- relational algebra expressions support.

No single system other than SQLify combines all the features above. SQLify also incorporates several important new features to further improve learning outcomes for students and assist instructors:

- query assessment (using CQ query equivalence);

- scoring correctness beyond binary correct/incorrect;

- use of peer review for assessment.

\subsection{Difficulties in Learning $S Q L$}

SQL has a simple syntax with a limited set of commands, yet it is possible to create complex queries with powerful results.

Even as early as 1978, Shneiderman (1978) describes difficulties encountered by students. Shneiderman's study showed students can produce queries equally well in natural language and in (at that time) SEQUEL, but produced many more errors before achieving a correct artificial query.

Sadiq et al. (2004) suggest the "straight forward syntax of the SQL SELECT command is often misleading, and generates an impression of simplicity in learners' minds. Sadiq goes on to compare the declarative nature of programming languages, which require users to think in steps, with SQL, where users think in sets which can be difficult for learners.

Mitrovic (1998) suggests learners struggle with the burden of having to memorize database schema and produce incorrect solutions because of this. Mitrovic also reports difficulty with grouping, join conditions and the difference between universal and existential quantifiers. These difficulties are also suggested by Kearns et al. (1997).

\subsection{SQL Tutoring and Assessment Systems}

In efforts to overcome identified problems associated with learning SQL, a number of tools have been created at various institutions, each allowing practice with feedback beyond that of a normal DBMS. Additional interactive feedback is used to overcome semantic misunderstandings and oversimplifications. Visualization of schema and query processessing is used to overcome memorization problems. Some SQL teaching tools also offer integration with assessment in undergraduate courses. A number of such tools are described in literature:

- SQLator, a tool created by the University of Queensland in 2004 and used extensively at the time (Sadiq et al. 2004);

- AsseSQL, a tool created by the University of Technology, Sydney also in 2004 (Prior 2003; Prior and Lister 2004);

- SQL-Tutor, described in (Mitrovic 1998) and developed at the University of Canterbury in Christchurch in 1998. This system attempts to provide intelligent feedback on students' attempts to create SQL queries;

- eSQL, proposed in 1997 to help visualize the process of query processing (Kearns et al. 1997); 
- $R B D I$ is a command line tool allowing students to practice their query writing skills in SQL, relational algebra and relational calculus. An extension of this, WinRBDI, is described in literature (Dietrich, Eckert and Piscator 1997).

All systems are used to teach students to write SQL statements. SQLator and AsseSQL are used to assess student queries and will be the focus of the remaining review.

Prior and Lister (2004) present AsseSQL as an online tool which allows entry and execution of SQL queries by students. They suggest an electronic interface creates a more authentic task than writing queries on paper and may encourage a deeper learning approach. Students are allowed access to AsseSQL for practice, but the ultimate use of this system appears to be in closed examinations under supervised, time constrained conditions within a computer laboratory. As well as being given a problem to solve, students are shown the desired result of the query they are to write as part of the problem description; this is justified as an attempt to overcome students' poor English skills. Apart from being online, these conditions and aids appear to create an unauthentic setting for student learning. Professional database users do write queries with computers, but not in these conditions. They will not know the results of a query before they create it. The system provides immediate feedback, but this is limited to the correctness of the solution provided by the student. No comments or suggestions for improvement are provided. While this reduces the marking load on instructors, it does not correct students' misunderstandings or encourage further learning. Three forms of evaluation on AsseSQL are provided: results of a student attitudinal survey, evidence of a focus group and opinions of instructors. These evaluations show that an online SQL assessment tool is worth pursuing; however no validation of the system against student outcomes or results is suggested.

A clearer validation is presented by Sadiq et al (2004) for SQLator which showed student engagement through voluntary student practice statistics and improved results in final grades. The SQLator system attempts to judge the correctness of submitted queries and also provide intelligent feedback to "enhance [student's] learning experience." It is not clear how student results are used for assessment purposes or how students are motivated to use SQLator.

The papers describing the above mentioned tools focus on the resulting improvements in educational outcomes. None of these papers describe in detail the inner workings of their system and show minor regard to relational database theory. There is little mention of SQL teaching tools outside computing education.

Both AsseSQL and SQLator apply only a simple binary grading to queries submitted by students. While the creators of AsseSQL argue for the sufficiency of this right-orwrong approach, a greater objective discrimination of quality is possible using a more sophisticated grading system (see Section 2).

Both AsseSQL and SQLator use heuristic methods to evaluate queries entered by students. This involves running the submitted query on a test database, and comparing the output with that of the query included in the definition of the problem. It is possible for students to cheat by creating simple queries that produce the desired output for the given database instance, which cannot be generalized to all instances of the database. For example, assume a student was asked to write a query to obtain names of employee who work 
in IT Department. With two tables, an employee table and a department table, normally a join would be required to discover the department ID of the IT Department and then discover which employees are in that Department.

SELECT name FROM emp, dept WHERE emp.deptno=dept.deptno AND dept. deptname = 'IT';

A student, seeing an instance of the database and knowing that the deptno for the IT Department is 5 , could cheat by writing a query which produces the correct output without consulting the dept table.

SELECT name FROM emp WHERE deptno=5;

Sadiq et al. (2004) suggest SQLator, using heuristic comparison, marks a query as correct in $95 \%$ of relatively easy test cases. The success of the heuristic depends in part on the database instance used in the test; a badly designed instance reduces the level of correctness of this method. Prior and Lister (2004) propose extending AsseSQL to run an additional test on a second database not shown to students. While this may increase the correctness of evaluation, it is still only another heuristic test.

In database theory it is well known that queries in the class of Conjunctive Queries (CQ) possess an important property: it is decidable whether two queries are equivalent. The CQ class is a significant subset of SQL excluding the set operators (union, difference, intersection) and grouping statements. In the introductory Database Systems course at the University of Southern Queensland, more than 70\% of the time spent on SQL is reserved for such queries. For this class of queries a computer assisted assessment tool should be able to evaluate correctness of submitted queries with $100 \%$ accuracy by examining the submitted queries alone. For queries that are not in CQ, a heuristic approach can still be used by comparing the output instance of the submitted query with that produced by the instructor's set solution query. Such queries can then be flagged for instructor moderation.

Some practical considerations regarding database systems are also unaddressed in the existing literature. The use of the DISTINCT keyword or sorting in a query makes it impractical to test equivalence using only the heuristic described above. Furthermore, both AsseSQL and SQLator seem vulnerable to SQL injection attacks. These include attempts to make unauthorised modifications to a database by taking advantage of the level of access provided by the interface. Care must be taken to check or rewrite a submitted query before it is evaluated by the database server.

The techniques used in automated SQL teaching and assessment tools can be readily used for relational algebra as well. This requires only a user-friendly (and, desirably, pedagogically sound) interface for entering relational algebra statements, and additional logic to convert students' algebra expressions into SQL. This conversion process is a welldocumented procedure. This is not used in SQLator or AsseSQL but is partially achieved in $R B D I$.

With an automated assessment system it is possible to involve students in the assessment process using peer review. According to Saunders (1992) peer learning is advantageous as "it offers the opportunity for students to teach and learn from each other, providing a learning experience that is qualitatively different from the usual teacher-student 
interactions". Peer review can be conducted in a number of ways. The form used with SQLify takes a student's submission and allows it to be reviewed by a number of studentpeers, a process automated by the system and overseen by an instructor. Peer review allows students to evaluate the work of others which requires higher order thinking skills (Bloom 1956) through evaluating the work of peers and reflecting on their own work. With peer review, students also receive feedback from more than one source enriching the learning experience for students. Receiving feedback from peers can encourage a community of learning (Brook and Oliver 2003) which can in turn further encourage higher order thinking. Peer review involves students in the assessment process, encouraging increased engagement in the course and ultimately improved learning outcomes (de Raadt, Toleman and Watson 2005). Peer review has been successfully incorporated in the assessment of student work in various fields, including computing (Kurhila et al. 2003; de Raadt et al. 2005; Chapman 2006; de Raadt, Toleman and Watson 2006) with demonstrated improvements in students' learning outcomes. Peer review, when used as an assessment tool, can also reduce the assessment workload of instructors. Both AsseSQL and SQLator create only a single channel of communication between the student and the instructor via the system. No other forms of communication (e.g., peer to peer) are mentioned as being part of these systems or used along-side these systems.

In the next section, the SQLify system is proposed. The following section shows examples of a hypothetical implementation of SQLify. In the final section, conclusions and possible future extensions of the system are suggested.

Table 1

Comparison of existing tools and SQLify

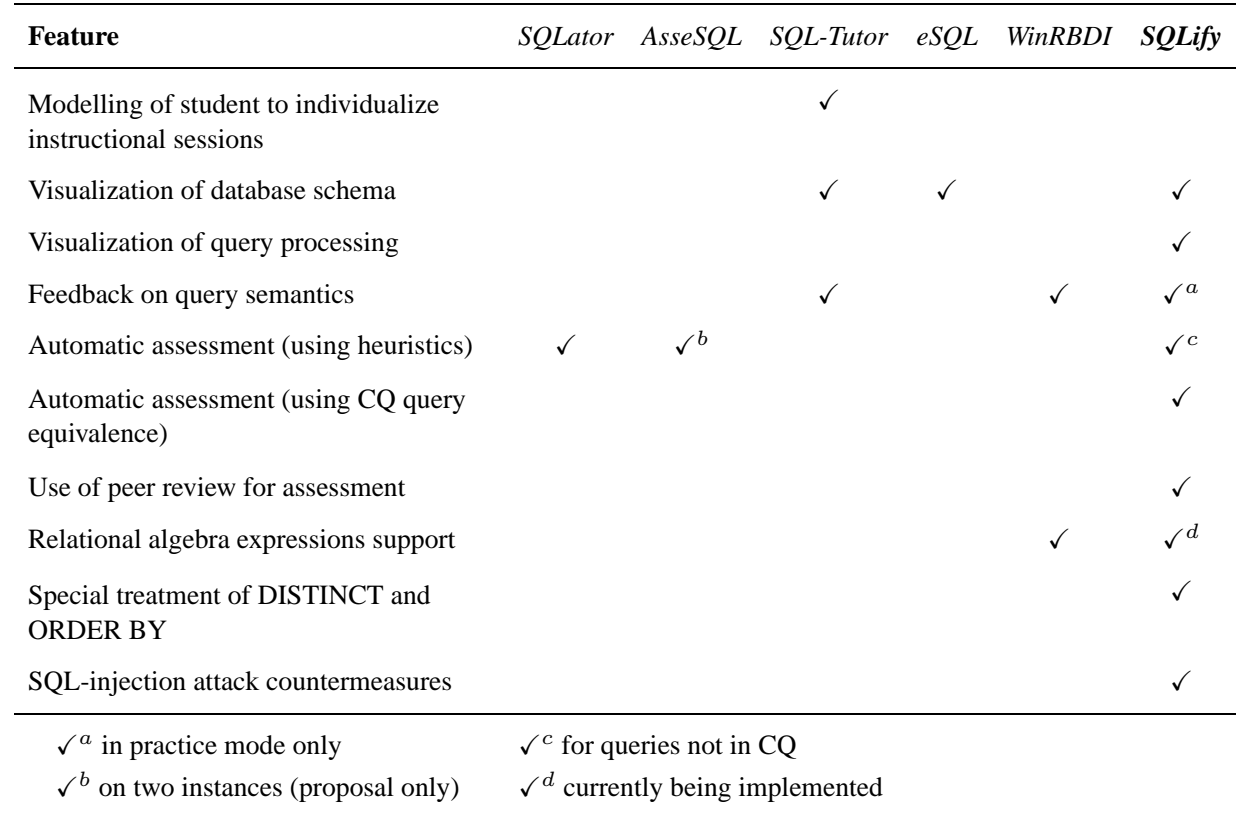




\section{The SQLify Proposal}

Having compared and evaluated existing computer assisted learning and assessment tools, we now turn to the description of SQLify which aims to improve on existing solutions on several different fronts. Specifically, the following requirements have driven the design of SQLify:

- provide rich feedback to students in an automated and semi-automated fashion;

- employ peer-review to enhance learning outcomes for students (through students conducting evaluations and receiving feedback from more sources);

- use database theory combined with peer review effectively to yield a wider range of final marks;

- judge the accuracy of reviews performed by students;

- reduce the number of necessary moderations conducted by instructors, freeing them for other forms of teaching.

Hence, the main focus of SQLify is computer assisted practice and assessment using a sophisticated automatic grading system in combination with peer review.

The current implementation of SQLify, with a demonstration of available functionality is viewable from the project website (Dekeyser and de Raadt 2006).

\subsection{Use of SQLify}

The SQLify system is intended to assess a student's query writing skills through an online interface in the context of assignments and preparing for assignments. Student use of the system can be seen to fall into a series of phases.

1. Trial and submission.

2. Reviewing peers' submissions.

3. Receiving feedback and marks.

As show in Fig. 1 a student will submit solutions to a number of problems. The value of their submission will be judged by peers, the SQLify system and ultimately by the instructor.

Students complete reviews of (usually two) other students submissions for which they are awarded marks. The accuracy of their submission determines the mark they receive for reviewing.

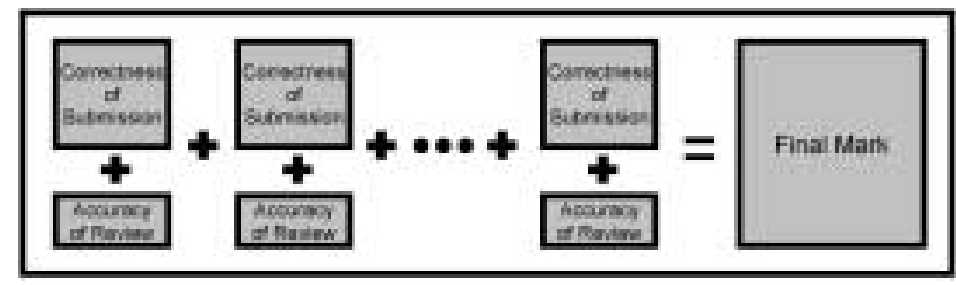

Fig. 1. Components of student's mark. 
Finally the marks they received for submission and the accuracy of their reviews is summed for each question to form a final mark.

The following subsections describe in detail these three phases.

\subsubsection{Trial and Submission}

Students are able to develop and trial their query answers to a specific set of problems using SQLify and immediately see how the automatic grading system evaluates their work. The SQLify system will give one of (a limited set of) the levels of correctness shown in Table 2. Students may trial their solutions indefinitely without submitting their query answers. The mark they are shown during this trial period is not necessarily what they will receive from the instructor for the correctness of their submission; this is given later by the instructor under advisement of the student's peers and the SQLify system. When the student is happy with their work they may proceed to submitting query answers to assignment problems.

Students completing assignments using SQLify will typically be given a number of English-language problems (say three to five) that he or she would translate to SQL or Relational Algebra. The problems are well defined descriptions of authentic, real world problems. Students' query answers are submitted through a web form shown in Fig. 2

Table 2

Levels implied by evaluation sentences. Different sentences may be used by reviewing students, the SQLify system, and the instructor. Internal assessment values (last column) are possible values for each level which may be set by the instructor

\begin{tabular}{|c|c|c|c|c|c|}
\hline Level & Description & $\begin{array}{l}\text { Student } \\
\text { can use }\end{array}$ & $\begin{array}{l}\text { System can } \\
\text { use }\end{array}$ & $\begin{array}{l}\text { Instructor } \\
\text { can use }\end{array}$ & $\begin{array}{l}\text { Possible } \\
\text { internal value } \\
\text { for query }\end{array}$ \\
\hline LO & $\begin{array}{l}\text { Syntax, output schema, and query } \\
\text { semantics are incorrect }\end{array}$ & $\checkmark$ & $\checkmark$ & $\checkmark$ & $0 \%$ \\
\hline L1 & $\begin{array}{l}\text { Syntax is correct, schema and } \\
\text { semantics incorrect }\end{array}$ & $\checkmark$ & $\checkmark$ & $\checkmark$ & $20 \%$ \\
\hline L2 & $\begin{array}{l}\text { Syntax and schema correct, semantics } \\
\text { are incorrect }\end{array}$ & $\checkmark$ & $\checkmark$ & $\checkmark$ & $30 \%$ \\
\hline $\mathbf{L 3}$ & $\begin{array}{l}\text { Syntax and schema correct, semantics } \\
\text { are largely incorrect }\end{array}$ & & & $\checkmark$ & $40 \%$ \\
\hline L4 & $\begin{array}{l}\text { Syntax and schema correct, semantics } \\
\text { seem largely incorrect (not sure) }\end{array}$ & $\checkmark$ & & & $70 \%$ \\
\hline L5 & $\begin{array}{l}\text { Syntax and schema correct, semantics } \\
\text { are just adequate }\end{array}$ & & & $\checkmark$ & $80 \%$ \\
\hline L6 & $\begin{array}{l}\text { Syntax and schema correct, semantics } \\
\text { seem largely correct (not sure) }\end{array}$ & $\checkmark$ & $\checkmark$ & & $90 \%$ \\
\hline L7 & $\begin{array}{l}\text { Syntax, schema, and semantics are } \\
\text { correct }\end{array}$ & $\checkmark$ & $\checkmark$ & $\checkmark$ & $100 \%$ \\
\hline
\end{tabular}




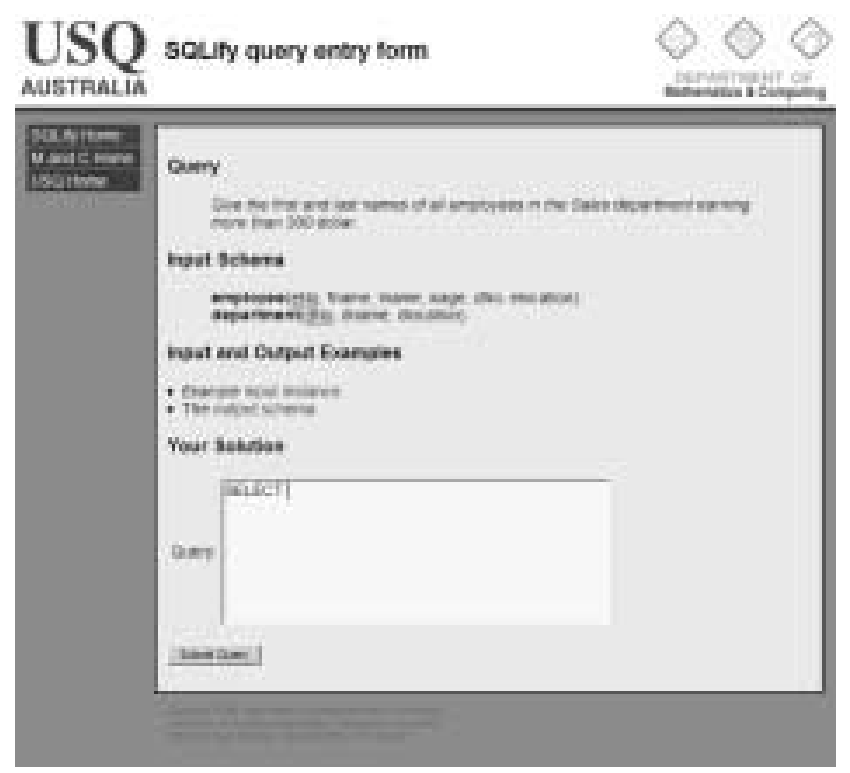

Fig. 2. The form for query input.

which demonstrates a simple query description, the database schema, links to a visualization of an instance of the database and to an output schema, and a text area where the student can enter their query answer. The student can also be supplied with hints and comments, and also with the desired output schema for the query (not the desired output instance), if so determined by the creator of the problem.

To evaluate relational algebra expressions students use an interface that helps construct syntactically correct algebra expressions. An algorithm translates the submitted algebra expression to an equivalent SQL statement. The generated statement is then processed in the same way as a normal SQL statement.

Once a query is submitted to the system it is checked for SQL injection attacks. First, tables referenced in the FROM clause of the submitted statement need to appear in the source database schema, or the query will be rejected. Second, the WHERE clause is analyzed and possibly rewritten using mainstream SQL injection countermeasures.

Students are not notified if their submitted queries are syntactically incorrect (although they should have been able to determine this themselves by trialing their submission).

Students receive feedback about their submission in the final phase (see Section 2.1.3).

\subsubsection{Reviewing Peers' Submissions}

SQLify is used with a pre-existing peer review system defined in (de Raadt et al. 2005) and integrated with SQLify as follows.

After submitting, most students will be able to immediately proceed to complete reviews allocated to them. A small pool of early-submitting students (usually four) will 
wait until enough submissions have accumulated before they can proceed to reviews. The system facilitates reviewing in a way that maintains anonymity.

When the system has allocated reviews to a student, reviewing can commence. The student is presented with a similar screen to what they used to input their query answer during the initial submission phase, but where they were previously able to enter their answer the system now shows a read-only query given by a peer. The reviewing student additionally sees the result of applying the query on the relevant database instance. The reviewing student then selects a level described by a sentence from the list shown in Table 2 that best describes their assessment of the correctness of the query answer. The list of possible levels given in Table 2 shows all available levels of which the reviewing student may choose levels marked with a tick in the column titled "Student can use". No corresponding internal values are shown to the reviewing student. Reviewing students may express uncertainty by choosing a sentence that includes "I am not sure". This allows the system to assign a wider range of marks to reviews, but is also used to flag potential problems that need to be moderated by an instructor.

By linking automatic assessment of queries with reviews given by students, it is not only possible to evaluate the correctness of queries, but also the accuracy of reviewers in judging that query. Students will review the work of two peers knowing that the reviews they perform will also be assessed as shown in Fig. 3.

A student's review accuracy should be marked high when the level they selected for a peer's query answer is very similar to the level ultimately determined for that query answer by the instructor. Conversely, accuracy should be marked low when it differs greatly from the instructor's correctness mark. Hence, the formula for marking accuracy of a review performed by a student is quite simple.

accuracyMark = $100-\mid$ correctnessMark - studentMark $\mid$

In other words, the mark given to a reviewer for the accuracy of their review depends on the difference to the correctness mark assigned by instructor. Note that this formula

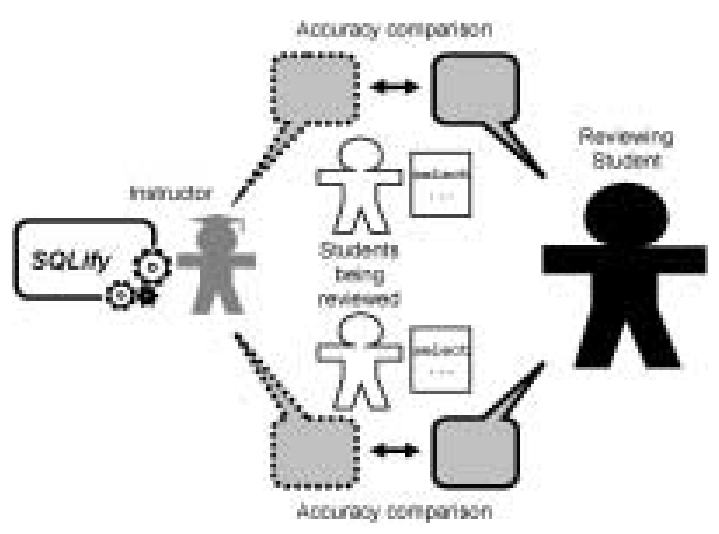

Fig. 3. Checking student's peer review accuracy. 


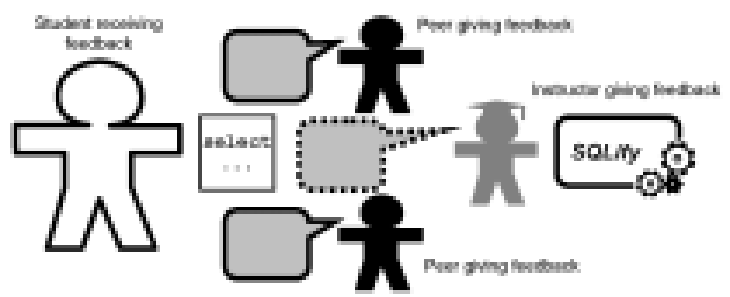

Fig. 4. Feedback received by the student

has the additional effect that when a student has signaled uncertainty (by picking level L4 or L6) they will not be awarded full marks for this review.

Giving fellow students a false high or low level evaluation which differs for the mark applied by an instructor will lose marks for the reviewing student.

As well as judging correctness levels for their peer's query answers, reviewing students are also required to leave a comment. Students are encouraged to give comments of praise or positive suggestions for improvement. This is arguably the most valuable part of the reviewing process for both the reviewer and the reviewee.

For the reviewee receiving peer feedback means they will receive feedback from more sources than just the instructor or the system (see Fig. 4). The information contained in comments can encourage a more personal relationship among students (even anonymously) and between instructors and students (de Raadt et al. 2005).

For instructors, adding a comment allows elaboration on why a student may have lost marks and positive encouragement on their progress. The instructor may draw on a list of previously created comments to speed up the moderation process. This also provides consistency when multiple instructors are performing moderations.

\subsubsection{Receiving Feedback and Marks}

When reviews are complete, the SQLify system suggests its own correctness level which is presented to the instructor alongside peer reviews so that a final correctness mark can be set. The system suggests a correctness level in the following manner with levels drawn from Table 2 .

\section{LO The submission is syntactically incorrect}

The submitted query is sent to the database engine which returns a syntax error. The system is certain that the query is syntactically incorrect, so the level suggested by the system is $\mathrm{L} 0$.

\section{L1,L2 The submission is syntactically correct}

The query is accepted by the database, upon which the system checks whether the output schema is the same as the one produced by the solution query (supplied by the instructor). The system can determine this exactly, and suggests a level of L1 if the condition is not met, and L2 if the condition is satisfied.

L6 The submission produces a result that is probably correct but needs to be checked or compared with peer marks 
The query passes the output schema test, and now undergoes examination of its semantics. If the query does not belong to the Conjunctive Query (CQ) class, only a heuristic approach is possible. If the heuristics determine that the query is correct, there is only a small chance that in fact the query is not semantically correct (see Section 1.2). The system suggests a level of L6 if the test is successful, and $\mathrm{L} 2$ if it is not.

\section{L7 The submission is certainly correct}

In case the query belongs to the CQ class, it is possible to algorithmically decide whether it is semantically equivalent to the set solution query. If it is the system suggests a level of L7, otherwise it suggests level L2.

There is a gap between levels L2 and L6; levels L3 to L5 cannot be chosen by the system. This is because the SQLify system cannot determine how good or how bad a query is that has been proven to be semantically incorrect. Hence a combination of peer review and instructor intervention is used to come up with a wider range of accuracy marks. Thus, as well as enhancing the learning experience of students, the peer review process also plays a practical role in moderating the mark proposed by the system and in flagging possible problems to the instructor.

When all reviews of a student's work are complete and the system has suggested a correctness level, the instructor allocates a mark for the student's work based on the levels suggested by peers and by the SQLify system. Instructors must attend to submissions that have been assessed differently by each peer or by the system. Past experience (de Raadt et al. 2006) has shown that in at least half of normal submissions, peers alone are able to achieve non-conflicting reviews, so this means moderation is most likely to be unnecessary. In most cases the system can determine a level for a solution with absolute certainty so this further eases the marking load of the instructor.

One of the clearest benefits of using a single-step peer review system it that students receive feedback about their submission as soon as a peer has completed their review. Compared with a normal instructor marked assignment where students must wait until after the assignment deadline for feedback, previous use of the approach suggested here returns feedback to students within hours (de Raadt et al. 2006).

Once the peer review process is completed and the instructor has assigned marks to students the SQLify system can calculate a final mark for each student.

The system suggests a final mark for a student's assignment. It does so by summing both the correctness marks for each query answer and accuracy marks for the reviews conducted by that student. The weighting of correctness and review accuracy for each problem in each assignment could be varied according to the effort for each. An example would be weighting the correctness marks to $70 \%$ of the entire assessment and review accuracy marks to $30 \%$. The instructor then chooses to accept or modify the suggested mark. Such marks may be released individually by the instructor or en masse. Details of how an accuracy mark is determined by the system and how an instructor determines their accuracy mark are given in (Dekeyser, de Raadt and Lee 2006). 


\section{Example Run Through of SQLify System}

To illustrate the workings of SQLify, two query problems are presented together with a description of how they would be evaluated.

The problems make use of a database with the following schema.

employee(eNo, fname, lname, wage, dNo, elocation)

department $(\underline{\mathrm{dNo}}$, dname, dlocation)

\subsection{Problem Example 1}

The first query problem (QP1) is an example of a Conjunctive Query (a problem in class $\mathrm{CQ}$ ). In this class it is possible to conclusively determine if a supplied query is correct without employing heuristic comparison.

Give the first and last names of all employees in the Sales department earning more than 300 dollars (QP1).

The instructor supplies a solution query that will be used by the system to test queries submitted by students.

SELECT fname, Iname FROM employee E, department D

WHERE E.dNo = D. dNo AND dname = 'Sales' AND wage > 300;

The following are two queries submitted by students. They are both different to the solution presented by the instructor, but both can be proved to be semantically equivalent to the instructor's solution query and are therefore considered correct (refer to Table 2).

The following query is an incorrect query answer to the above problem (QP1).

Table 3

Two correct query solutions (SA1 and SA2) in CQ class and how they were evaluated

\begin{tabular}{llccc}
\hline Submitted query & sys & stdl & std2 \\
\hline SELECT fname, lname FROM employee JOIN & L7 & L6 & L7 \\
department ON dNo WHERE dname = 'Sales' AND & & & \\
wage > 300; & L7 & L7 & L4 \\
SELECT fname, lname FROM employee E WHERE wage & & & \\
$>300$ AND EXISTS (SELECT * FROM department D & & & \\
WHERE E. dNo = D.dNo AND dname $=$ 'Sales'); & & &
\end{tabular}

Table 4

An incorrect solution (SA3) in CQ class and how it was evaluated

\begin{tabular}{lccc}
\hline Submitted query & sys & std1 & std 2 \\
\hline $\begin{array}{l}\text { SELECT fname, lname FROM employee E WHERE dname } \\
\text { L2 }\end{array}$ & L6 & L4 \\
$=$ 'Sales' AND wage > 300; & & & \\
\hline
\end{tabular}




\subsection{Problem Example 2}

The next problem (QP2) involves a query that is not in CQ class.

List all locations where there is either an employee or a department (QP2).

The following is an instructor's solution query for this problem.

(Select elocation From employee) UNION

Table 5 shows an incorrect solution to this problem.

\subsection{Marking Query Correctness}

When the system has evaluated a submitted query and peer reviews are complete for that query the system will recommend a mark to the instructor. The instructor can then assign an accuracy mark for the query. Table 6 shows, for each row, the correctness marks for a particular query submitted by a student, as given by the system itself (sys), and two peers reviewing the query answer ( $s t d l$ and $s t d 2$ ). In addition, a suggested mark is shown calculated by SQLify on the basis of sys, std1 and std2. Refer to (Dekeyser et al. 2006) for details on how this is achieved. Finally, the accuracy mark assigned by the instructor is listed; this mark may or may not be the same as the suggested mark.

The internal values corresponding to levels given in Table 2 are not hard-coded into the system. The instructor using SQLify can set these values during use of the system. Hence, percentages given to query answers can be different in practice from the ones shown here.

Table 5

An incorrect solution (SA4) in CQ class and how it was evaluated

\begin{tabular}{lccc}
\hline Submitted query & sys & stdl & std2 \\
\hline $\begin{array}{l}\text { Select loc FROM employee, department WHERE 1OC } \\
\text { elocation OR loc }=\text { dlocation; }\end{array}$ & L2 & L3 \\
\hline
\end{tabular}

Table 6

Correctness marks for submitted query answers

\begin{tabular}{cccccccccc}
\hline $\begin{array}{l}\text { Stu- Prob- } \\
\text { dent } \\
\text { lem }\end{array}$ & $\begin{array}{l}\text { query } \\
\text { mark (sys) }\end{array}$ & $\begin{array}{r}\text { Reviewer } \\
\text { Mark } \\
(\text { std1) }\end{array}$ & $\begin{array}{r}\text { Reviewer } \\
\text { Mark } \\
(s t d 2)\end{array}$ & $\begin{array}{l}\text { Suggested } \\
\text { mark }\end{array}$ & $\begin{array}{l}\text { Correctness } \\
\text { mark set by } \\
\text { instructor }\end{array}$ \\
\hline 1 & QP1 & SA1 & L7 & 3 & L6 & 5 & L7 & L7 & L7 (100\%) \\
1 & QP2 & SA4 & L2 & 4 & L2 & 5 & L3 & L3 & L3 (40\%) \\
4 & QP1 & SA2 & L7 & 1 & L7 & 3 & L4 & L7 & L7 (100\%) \\
5 & QP1 & SA3 & L2 & 1 & L6 & 2 & L4 & L4 & L4 (70\%) \\
\hline
\end{tabular}




\subsection{Checking Accuracy of Reviews}

Table 7 lists one row per peer review that is performed in the context of an assignment. The first row, for instance, shows that student 1 was a reviewer for a query (SA2) submitted by student 4 in answer to query problem QP1. Student 1 gave this query answer a correctness mark of L7. The accuracy mark for the submitted query answer given by the instructor was also L7. Hence, the accuracy mark for this particular review is 100 . For the next review performed by this student there is a difference between the correctness mark given by this student and the accuracy mark set by the instructor. This difference causes their mark for accuracy to be reduced.

\subsection{Calculating a Final Mark}

The last table below summarizes the various marks that a particular student received for various query problems and for the reviews performed. A weighted final mark is given in the last row using the suggested weightings of $70 \%$ for correctness and $30 \%$ for accuracy of reviews.

Table 7

Accuracy marks for reviews

\begin{tabular}{cccccccc}
\hline Reviewer & Reviewee & Problem & $\begin{array}{l}\text { Sub- } \\
\text { mission }\end{array}$ & $\begin{array}{l}\text { Reviewer's } \\
\text { mark for } \\
\text { submission }\end{array}$ & $\begin{array}{l}\text { Accuracy } \\
\text { mark set by } \\
\text { instructor }\end{array}$ & $\begin{array}{l}\text { Diffe- } \\
\text { rence }\end{array}$ & $\begin{array}{l}\text { Accuracy } \\
\text { mark for } \\
\text { this review }\end{array}$ \\
\hline 1 & 4 & QP1 & SA2 & L7 & L7 & $0 \%$ & $100 \%$ \\
1 & 5 & QP1 & SA3 & L6 & L4 & $20 \%$ & $80 \%$ \\
\hline
\end{tabular}

Table 8

Final mark calculation

\begin{tabular}{lll}
\hline Student: 1 & & \\
Correctness marks & QP1 & $100 \%$ \\
(Weight 70\%) & QP2 & $50 \%$ \\
& QP3 & $70 \%$ \\
Review accuracy & QP1 & $100 \%$ \\
(Weight 30\%) & QP2 & $80 \%$ \\
& QP3 & $50 \%$ \\
Final Mark & & $74 \%$ \\
\hline
\end{tabular}




\section{Conclusions}

In this paper a small set of existing tools used for teaching and assessing SQL writing skills was reviewed. The tools were evaluated from both from Computing Education and Database Theory perspectives, noting possible areas of enhancement.

A new tool called SQLify was introduced which is used for practice and submission of database query assignments. Central to SQLify is the use of an intricate automatic grading system and of peer review. The main reason for including peer review is to offer the students a richer learning experience. Additionally, the peer reviews will assist in the assessment of assignments.

SQLify uses a relatively complex method to suggest marks for assignments, designed to:

- yield a much wider range of accuracy marks than simply correct or incorrect;

- employ peer review of assignment work by students encouraging evaluation and producing more sources of feedback to students;

- utilize database theory to enhance computer assisted grading;

- set high quality demands for student reviews, yielding higher learning outcomes; and

- reduce the number of necessary moderations by course instructors.

Each of these objectives must be made transparent to students. Students are informed of the possible learning benefits for students and the time-saving benefits for instructors. Students must be made aware of how the marking approach will be used to assess their work and their reviews and how they must use the system to succeed in assessments.

SQLify has been prototyped and implemented and is ready to be used in a live course by the end of 2006, with the exception of Relational Algebra support. Student use of the system will be monitored. The usefulness of the system as perceived by students and instructors will then be evaluated. Any change in student outcomes will be measured.

With this new tool it will also be possible to effectively distinguish specific problems within the areas of difficulty suggested in Section 1.1, allowing feedback into the existing curriculum to improve teaching in these areas.

\section{References}

Bloom, B.S. (1956) Taxonomy of Educational Objectives. Edwards Bros., Ann Arbor, Michigan.

Brook, C., and R. Oliver (2003). Online learning communities: Investigating a design framework. Australian Journal of Educational Technology, 19(2), 139-160.

Chapman, O.L. (2006). The White Paper: A Description of CPR. Retrieved February 23, 2006. http: / / cpr . molsci.ucla.edu/cpr/resources/documents/misc/CPR_White_Paper.pdf

de Raadt, M., M. Toleman and R. Watson (2005). Electronic peer review: A large cohort teaching themselves? In Proceedings of the 22nd Annual Conference of the Australasian Society for Computers in Learning in Tertiary Education (ASCILITE'05). Brisbane, QUT, Brisbane, pp. 159-168.

de Raadt, M., M. Toleman and R. Watson (2006). An effective system for electronic peer review. International Journal of Business and Management Education, 13(9), 48-62.

Dekeyser, S., and M. de Raadt (2006). SQLify Project Website. Retrieved May 15, 2006.

http://www.sci.usq.edu.au/projects/sqlify/ 
Dekeyser, S., M. de Raadt and T.Y. Lee (2006). Computer Assisted Assessment of SQL Query Skills. Retrieved 1st September, 2006.

http://www.sci.usq.edu.au/research/workingpapers/sc-mc-0610.ps

Dietrich, S.W., E. Eckert and K. Piscator (1997). WinRDBI: a Windows-based relational database educational tool. In Proceedings of the Twenty-eighth SIGCSE Technical Symposium on Computer Science Education. San Jose, California, United States, ACM Press, pp. 126-130.

Kearns, R., S. Shead and A. Fekete (1997). A teaching system for SQL. In Proceedings of the 2nd Australasian Conference on Computer Science Education. Melbourne, Australia, pp. 224-231.

Kurhila, J., M. Miettinen, P. Nokelainen, P. Floreen and H. Tirri (2003). Peer-to-peer learning with open-ended writable Web. In Proceedings of the 8th Annual Conference on Innovation and Technology in Computer Science Education (ITiCSE '03). Thessaloniki, Greece, ACM Press, pp. 173-178.

Mitrovic, A. (1998). Learning SQL with a computerized tutor. In Proceedings of the Twenty-ninth SIGCSE Technical Symposium on Computer Science Education SIGCSE '98. Atlanta, United States, ACM Press, pp. 307-311.

Prior, J. (2003). Online assessment of SQL query formulation skills. In Proceedings of the Fifth Australasian Conference on Computing Education. Adelaide, Australia, Australian Computer Society, pp. 247-256.

Prior, J., and R. Lister (2004). The backwash effect on sql skills grading. In Proceedings of the 9th Annual SIGCSE Conference on Innovation and Technology in Computer Science Education. Leeds, UK, ACM Press, pp. 32-36.

Sadiq, S., M. Orlowska, W. Sadiq and J. Lin (2004). SQLator: an online SQL learning workbench. In Proceedings of the 9th Annual SIGCSE Conference on Innovation and Technology in Computer Science Education (ITiCSE '04). Leeds, UK, ACM Press, pp. 223-227.

Saunders, D. (1992). Peer tutoring in higher education. Studies in Higher Education, 17(2), 211-218.

Shneiderman, B. (1978). Improving the human factors aspect of database interactions. ACM Trans. Database Syst., 3(4), 417-439.

M. de Raadt is a lecturer at the University of Southern Queensland, Australia. Michael's research focuses on teaching problem solving skills to novice programmers. Michael is also interested in online teaching and assessment including electronic peer review.

S. Dekeyser is a senior lecturer in the Department of Mathematics and Computing at the University of Southern Queensland in Australia. He obtained his $\mathrm{PhD}$ from the University of Antwerp, Belgium, in 2003 for his work on concurrency control techniques for semistructured databases and XML. His main interests are databases, document computing, Web technology, and computing education.

T.Y. Lee graduated from the University of Southern Queensland as a master of professional IT in 2006. His masters' dissertation involved the design and implementation of the SQLify learning and assessment system. He currently lives in Malaysia.

\title{
Sisteminis besimokančiujų ịsivertinimas ir kompiuterizuotas besimokančiuju užklausu kūrimo vertinimas
}

\author{
Michael de RAADT, Stijn DEKEYSER, Tien Yu LEE
}

Per pastaruosius metus buvo pasiūlyta keletas žiniatinklio priemoniu, padedančiu besimokantiesiems konstruoti SQL užklausas ir taip pat vertinančiu besimokančiuju SQL programavimo gebejjimus. „SQLify“ - tai nauja mokymosi ir vertinimo priemoné, išplečianti galimybes: i jas ịtrauktas besimokančiuju ịsivertinimas ir automatinis vertinimas, paremtas duomenu bazių teorija, leidžiančia pateikti išsamesni grižtamaji ryšị besimokantiesiems. „SQLify“ skirtas auginti turtingą besimokančiujų mokymosi patirtị ir sumažinti vertinimo naštą mokytojams. Šiame straipsnyje „SQLify“ lyginama su esamomis priemonemis, taip pat pateikiamos naujos svarbios savybès. 